\title{
Thyroid switching and D727E polymorphism
}

Mustafa Altay ${ }^{1}$, Murat Dağdeviren², Gülsüm Biten Güven ${ }^{3}$, Derun Taner Ertuğrul1 ${ }^{1}$

${ }^{1}$ Keçiören Education and Research Hospital, Department of Endocrinology and Metabolism, Ankara, TURKEY

${ }^{2}$ Keçiören Education and Research Hospital, Department of Internal Medicine, Ankara, TURKEY

${ }^{3}$ Keçiören Education and Research Hospital, Department of Clinical Microbiology, Ankara, TURKEY

\section{OBJECTIVE}

Graves' disease and Hashimoto's hypothyrodism are common thyroid diseases. However, occurrence of both clinical disorders one after the other in the same patient, is not common.

\section{CASE REPORTS}

In this article, we presented two hypothyroid patients who developed clinical thyrotoxicosis during levothyroxine treatment. Both patients were treated with levothyroxine for a long time. Due to occurrence of clinical hyperthyroidism, levothyroxine treatments of the both patients were terminated. Although unmedicated follow-up for about six weeks period, recovery from thyrotoxicosis wasn't observed. Both of the patients were positive for $\mathrm{TSH}$ receptor antibody.

Figure 1. Tc $99 \mathrm{~m}$ scintigraphy of thyroid of the first patient

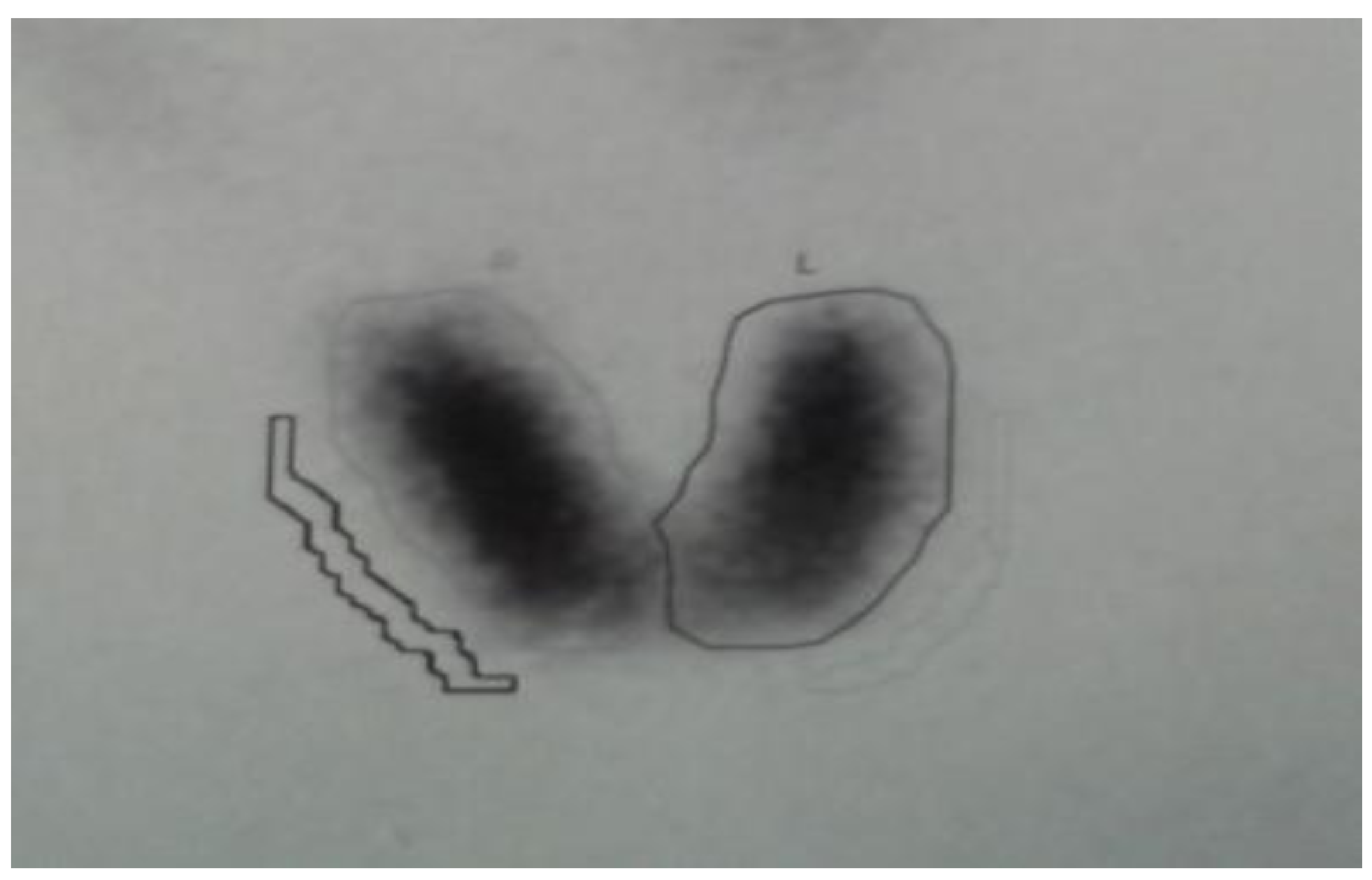
TSH FT3 FT4 TRAB Anti-TPO Anti-TG Treatment 